\title{
Airways Surface Liquid and Ion Transport - The Mechanism Maintained Patency
}

\author{
Iga Hołyńska Iwan*11, Inga Dziembowska ${ }^{2}$ and Dorota Olszewska Słonina ${ }^{1}$ \\ ${ }^{1}$ Department of Pathobiochemistry and Clinical Chemistry, Faculty of Pharmacy, Ludwik Rydygier Collegium Medicum in Bydgoszcz \\ Nicolaus Copernicus University in Torun, Poland
}

${ }^{2}$ Department of Pathophysiology, Faculty of Pharmacy, Ludwik Rydygier Collegium Medicum in Bydgoszcz Nicolaus Copernicus University in Torun, Poland

*Corresponding author: Iga Hołyńska Iwan, Laboratory of Electrophysiology of Epithelial Tissue and Skin, Department of Pathobiochemistry and Clinical Chemistry, Ludwik Rydygier Collegium Medicum in Bydgoszcz Nicolaus Copernicus University in Torun, Poland

\section{ARTICLE INFO \\ Received: 幽January 23, 2019 \\ Published: 㓞 February 11, 2019 \\ Citation: Iga Hołyńska I*, Inga D, Dorota Olszewska S. Airways Surface Liquid and Ion Transport - The Mechanism Maintained Pa- tency. Biomed J Sci \& Tech Res 14(3)-2019. BJSTR. MS.ID.002545.}

Keywords: Sodium; ENaC; Chloride; CFTR; Peliciliary Linking; Mucociliary Clearance

\begin{abstract}
The airway epithelium is covered with a thin, liquid protective layer - Airways Surface Liquid (ASL), which is a hydrogel, $3-50 \mu \mathrm{m}$ thick. ASL is created and maintained by water (AQPs) and ion transport, especially sodium (ENaC), chloride (CFTR, ClC), potassium, bicarbonate and calcium. Epithelial cells secrete mucins, which role is to transport ASL towards the upper airways. ASL is the first protection mechanism against solid particles and microorganisms inhaled with air. The proper ASL hydration and functioning are influenced by internal factors, such as the activity of ion channels (especially ENaC and CFTR) and water (AQPs), ciliary function, nerve endings irritation, influx of immunocompetent cells and current hormonal status. External factors affecting hydration are colonization by microorganisms and inhalation of irritants. Developing inflammation, cough, and drugs affect the functions of ion channels, thereby changing the ASL volume and composition, hindering or facilitating self-purifying and flow through airways. The aim of this study was to collect reliable scientific data concerning physiological and pathological changes in ASL volume and composition.
\end{abstract}

Abbreviations: ASL: Airways Surface Liquid; CF: Cystic Fibrosis; CFTR: Cystic Fibrosis Transmembrane Conductance Regulator; ClC: Chloride Channels; ENaC: Epithelial Sodium Channel; MCC: Mucociliary Clearance; MCT: Mucociliary Transport; PCL: Periciliary Linking; p.o. - Per Os, Orally; COPD - Chronic Obstructive Pulmonary Disease; RARs - Rapidly Adapting Receptors; SARs - Slowly Adapting Receptors

\section{Introduction}

The airway epithelium is covered with a thin, liquid protective layer - Airways Surface Liquid (ASL) [1]. ASL is created and maintained by water and ion transport, especially sodium and chloride [2-8]. Its task is to create an ideal environment that allows proper gas exchange through the respiratory epithelium [9-13]. ASL is engaged in the purification and maintenance of airways, which is associated with providing the right degree of hydration and protection against irritants [1,3,14-15]. It is the first protective barrier immobilizing microorganisms and impurities, which can then be easily expelled [16-23]. Regardless of the body's position, the direction of mucus transport is always cephalic and depends on the unchanging beats of cilia $[9,15]$. The composition and quantity of ASL, as well as the fluid movement is influenced by a number of internal and external factors, including drugs [9,15,22,2425]. The aim of this study was to collect reliable scientific data concerning physiological and pathological changes in ASL volume and composition.

\section{Airways Surface Liquid}

ASL is a product of ciliated cells, goblet cells, serous cells and submucosal glands. It is secreted in an amount of $5-40 \mathrm{ml} / 24$ hours $[9,14-15,26]$. The thickness of ASL is $3-50 \mu \mathrm{m}$, and its $\mathrm{pH}$ is around 7.6-7.7 [15-16]. ASL seems to be composed of two layers: the lower, periciliary linking (PCL) with the consistency of solsalt, and the more viscous, upper mucus layer, with a consistency of gel. However, some recent studies indicate that ASL may be actually more of a continuous hydrogel [15,24]. The thickness of PCL is usually constant and corresponds to the length of the cilia (3$10 \mu \mathrm{m}$ ) [25-26]. Both layers are continuously transported by the synchronized rhythmic beating of cilia (the mucociliary transport MCT) at a speed of about $3 \mathrm{~mm} / \mathrm{min}$ towards the pharynx $[1,17,26]$. 
There mucus can be either swallowed or expelled through the mouth [26]. The PCL consists mainly of water and mineral salts and its role is to moisturize the respiratory epithelium and facilitate the cilia-propelled mucus transport [1,26-28]. The main task of the viscous gel is to trap solid particles which are inhaled, including pathogens [12,29-30].

The composition of ASL determines its buffer and immune function [12,16,31-32]. The mucus layer is composed mostly of water (97\%), but also contains proteins, inorganic salts, lipids and nucleic acids derived from cells [25,31,34-35]. The viscosity of the mucus and its gel-like consistency are determined by the presence of mucins (30\% of mucus solids) [12,29-31,35]. Mucins are very large, highly anionic glycoproteins containing a high proportion of serine and threonine residues linked to sugar chains by their hydroxyl side groups (0-glycosylation) [35-38]. The number of glycosidic bonds and sulphide bridges determine the formation of specific, linear or branched structures of mucin molecules. Additionally, numerous oligosaccharides dispersed in the mucus provide attachment sites for surface receptors of bacteria and viruses [35-38]. The electric charge generated through transepithelial ion transport entice or repel mucins to the surface of the epithelium [29,37]. Macrophages residing in the airways, together with dendritic cells, are capable of phagocytosing bacteria, particulates, and apoptotic cells during such invasions [39]. Chemokines and cytokines released from macrophages and epithelial cells promote further neutrophil accumulation and local inflammation [16,23,31-32,39-40].

Inflammation can enhance the secretion of ASL up to $100 \mathrm{ml} /$ day, along with an increased number of immune cells and antiinfective components $[9,16,23,32,40]$. Factors affecting the wall of the respiratory tract such as pathogens enhance the secretion of mucins, increase the thickness of the mucus layer and accelerate the frequency of ciliary beats [15-17,22,25,33]. As a side note, excessive production of mucus, as well as its components, may cause airway obstruction, which leads to exacerbation of the primary disease, increased coughing and dyspnea [15-17,22,25,30]. Ciliary motion plays a critical role in the overall respiratory health of the upper airway $[17,28]$. These cilia beat at a native frequency and expel foreign particulates trapped in the layer of mucous out of the upper airway $[17,28]$. Disruption of ciliary motion can lead to severe respiratory diseases and compromised respiratory function [28]. It has been proven that ASL migrates more slowly in smaller airways than in larger airways [28], a factor which can additionally affect ion transport and volume regulation, as well as the thickness of the fluid lining [2,26,28].

During physiological respiratory activity, mucus is characterized by constant viscosity and elasticity, which enables continuous transport through the airways $[2,9,37]$. The pathological state causes disturbances in temperature, humidity and ion composition of mucus, enhanced production of mucins and inflammatory cells migration which lead to increase the viscosity and elasticity of mucus (Table 1) [12,15,23,25,30,41]. Impaired discharge of residual fluid induces inadequate mucociliary clearance (MCC) and colonization of the epithelium by microorganisms $[17,23,39,42]$. Electrolyte transport across human airway epithelium, followed by water movement is essential for normal mucociliary clearance and allows the maintenance of the aseptic condition of the respiratory tract $[4-5,7,14,21,24,41,43]$. The function of epithelial cells is to control and regulate ionic composition and the volume of fluids in the airways $[2,4,6,21,24,28,33,36,41,44-46]$. Therefore, continuous local fluid absorption and secretion following the cephalal ASL motion is necessary to maintain the proper thickness of the fluid lining throughout the entire airway space $[2,6-7,9,14,26,41,43,48]$. This evolatory system provides a balance between the two phases: the secretory phase - during which the chloride ions secretion takes place and the absorption phase - associated with the absorption of sodium ions (Figure 1) [2,4-5,7,14,42-45,48-49]. The inhibition of sodium ion conductivity determines the stimulation of the secretion mechanism for chloride ions which generate water inflow and increase the volume of the PCL $[2,4-5,7,41,48,50]$. Analogously, blockade of the chloride ion transport path provides the adsorption advantage of sodium ions $[2,17,41,43,48]$.

Table 1: Environmental and genetic factors influencing ASL changes.

\begin{tabular}{|c|c|c|}
\hline $\begin{array}{c}\text { Factor Affecting from the } \\
\text { Epithelium Side }\end{array}$ & Mechanism of ASL Quality Changes & Therapeutic Approach \\
\hline Bacterial infection* [29] & $\begin{array}{c}\text { Increase of concentrated ASL volume, colonization of epithelium, } \\
\text { influx of immunocompetent cells, cytokin and immunoglobulin } \\
\text { production, possible impaired cilia movement }\end{array}$ & $\begin{array}{c}\text { Support of the immune system, support of } \\
\text { expectorants, drugs, hydrated ASL }\end{array}$ \\
\hline Viral infection* [21] & $\begin{array}{c}\text { Changes depend on dysfunction of airways epithelium, possible } \\
\text { impaired cilia movement }\end{array}$ & Support of the immune system, \\
\hline COPD [47] & $\begin{array}{c}\text { In the early state, influx of immunocompentent cells and increase } \\
\text { of ASL density, afterwards emphysema symptoms: lack of ASL }\end{array}$ & Preservative treatment, physiotherapy \\
\hline Asthma [34] & $\begin{array}{c}\text { Influx of immunocompetent cells, especially eosynophiles, } \\
\text { increase of consistency of ASL, stimulation of CFTR, ENaC and } \\
\text { aquaporins }\end{array}$ & Glicocorticosteroids acting in airways, \\
$\beta$-adrenolytics, \\
\hline CF [15] & $\begin{array}{c}\text { CFTR dysfunction in chloride ions secretion, impaired cilia beats, } \\
\text { dehydration of ASL }\end{array}$ & Preservative treatment, physiotherapy \\
\hline Liddle syndrome [44] & ENaC dysfunction in sodium ions absorption & Preservative treatment \\
\hline Temperature increase [20] & Increased dehydration & Air heating, inhibited ENaC function \\
\hline Temperature decrease [17] & $\begin{array}{c}\text { CFTR dysfunction, interaction of proton exchanger with CFTR, } \\
\text { changes in ENaC conformation, changes of electric charge of } \\
\text { mucin }\end{array}$ & - \\
\hline pH decrease [13] & & \\
\hline
\end{tabular}




\begin{tabular}{|c|c|c|}
\hline pH increase $[16,37]$ & $\begin{array}{c}\text { Changes in CFTR regulatory function, decrease of antibacterial } \\
\text { mediators in ASL, induction of bacteria colonization }\end{array}$ & - \\
\hline Smoking $[23,36]$ & $\begin{array}{c}\text { Epithelial damage, overproduction of mucins and mucus, changes } \\
\text { in Ca concentration, increase of bacteria colonization, }\end{array}$ & Stop smoking \\
\hline
\end{tabular}

The effects of these phases are the periodic increase or decrease in the thickness of the mucus layer through the active migration of ions (sodium and/or chloride) and passive movement of water molecules from or to the interstitial space, which maintains ASL in a near-isotonic state $[2,6-7,9,22,42-43,48]$. Figure 1 Ion channels in tracheal epithelia and their role in regulating airway surface liquid levels in the airways. The results of studies on cultures of epithelial cells show that the thickness of the mucus layer can be adjusted without changing the thickness of the periciliary layer $[9,14]$. In other studies, it was found that in the place smaller airways join with larger ones, only the thickness of the mucus layer increased and the thickness of PCL did not change [1]. The results of studies on cultures of epithelial cells have shown that the thickness of the mucus layer can be adjusted without changing the thickness of the periciliary layer [12]. The mucus layer provides a reservoir of water for the PCL, the thickness of which determines the slippage of the mucus on the epithelial surface, which in turn has a direct impact on the effectiveness of mucociliary clearance $[1,9,12,36]$.

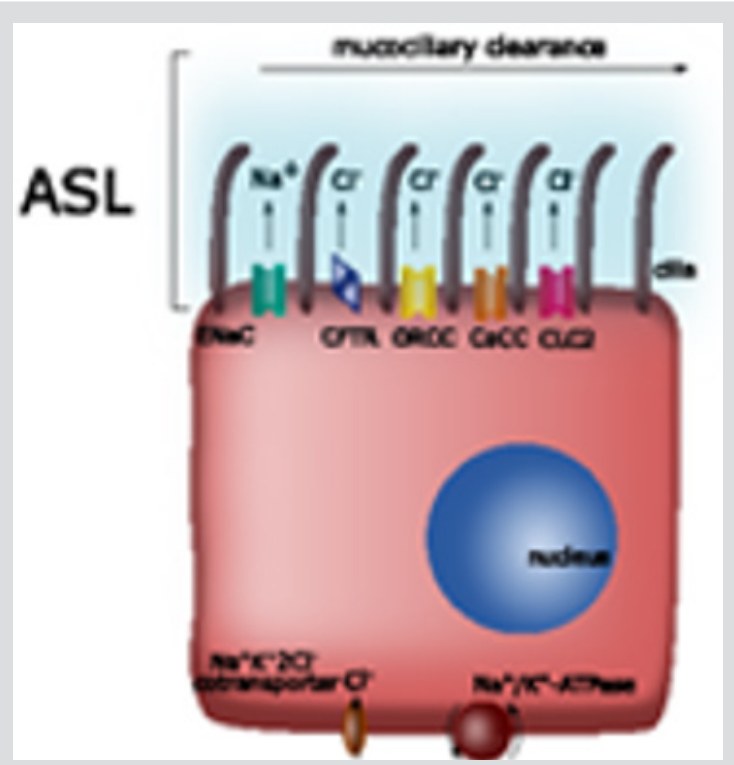

Figure 1: Ion channels in tracheal epithelia and their role in regulating airway surface liquid levels in the airways.

\section{Mucociliary Clearance (MCC)}

Mucociliary clearance is one of the most important mechanisms affecting the amount and composition of ASL [28,35,42]. The undisturbed function of the airway's self-cleaning mechanism is essential for efficient gas exchange and thus systemic homeostasis $[9,13]$. The main role of MCC is to cleanse respiratory epithelium from fine particles and pathogens and protect the respiratory tract from chemical damage and infections $[12,40,42]$. MCC is a complex of several cooperating mechanisms which include ion and water transport through the respiratory epithelial cells membrane and mucus formation as well as transport and expectoration supported by the cough reflex $[13,23,28,35,42]$. Although MCC is an independent protective mechanism, its functioning is reinforced by a cellular (phagocytic) and humoral immune response, that is; secretory antibodies - soluble immunoglobulin A [31,39]. Due to its complexity, the effectiveness of MCC is determined by many physiological and environmental factors including: age, sex, posture, sleep, physical activity, degree of air pollution, smoking and amount and adhesion of microorganisms (bacteria, fungi, viruses) [12,20,22,25].

Disorders may not only result from disease, but also may be one of the factors contributing to them. For example, disturbed MCC is observed in COPD, asthma, immobile cilia syndrome, cystic fibrosis and chronic bronchitis $[9,19,24,35,42,48]$. The optimal value of temperature in the tracheobronchial airways is $34-40{ }^{\circ} \mathrm{C}$. Increase of temperature results in dehydration of ASL, increased osmolality and intensification of chloride and water transport processes [20]. Decrease of temperature reduces hydration and water transport to ASL and increases absorption of sodium ions [17]. Mucociliary clearance in the airways depends on the flow of fluids through the respiratory epithelium [20,42]. Fluid movement results from an osmotic gradient conditioned by ionic motion, which is regulated by hormones and neurotransmitters [22,42]. Because the respiratory epithelium is a barrier, it has continuous contact with the external environment [21]. In order to be able to perform its physiological functions it must be constantly protected by a number of factors, including: mechanical mucociliary transport, components and elements contained in the mucus with bactericidal and bacteriostatic action and immune cells [12,19-20,34,40]. An additional, natural protective element of the respiratory tract and epithelium is the cough reflex.

\section{Ion and Water Transport}

Sodium Ion Transport: Absorption of sodium ions proceeds in two stages and is conditioned by the action of the epithelial sodium channel ( $\mathrm{ENaC}$ ) on the apical side and the sodium-potassium pump on the basolateral side of ciliated epithelial cells [4-5,11,44,51]. ENaC's activity affects the transport of other ions, including potassium, chloride and bicarbonate $[11,18,51]$. The ENaC allows for the transcellular transport of sodium ions, plays an important role in regulating the water level in cells and in maintaining sodium and water homeostasis $[4,6,11,51]$. ENaC is composed of three types of subunits: $\alpha, \beta, \gamma$, which are arranged in the following proportions: $2 \alpha: 1 \beta: 1 \gamma$ or $3 \alpha: 3 \beta: 3 \gamma[7,18,51]$. The sodium channel is permeable to $\mathrm{H}^{+}, \mathrm{Li}^{+}, \mathrm{Na}^{+}$, and impermeable to $\mathrm{K}^{+}$and $\mathrm{NH}_{4}^{+}$ions, due to their large size [18]. ENaC is expressed in the pulmonary alveoli and the airways, where it affects the absorption of sodium ions from the epithelial surface $[11,17,52]$. In humans, the $\alpha, \beta$ and $\gamma$ subunits are expressed strongly in the airways, while the expression of the $\gamma$-subunit is lesser in bronchioles $[7,51,53]$. Amiloride $[7,11,40,49]$ and benzamin [52] are specific inhibitors. 
Sodium ions penetrate inside the cell according to an electrochemical gradient through the sodium channel $[4,46,52]$. These ions are then removed from the cell via a sodium potassium pump into the submucosal space [44,52]. The removal of one sodium ion accompanies the transport of one potassium ion into the cell $[4,18,51,53]$. In newborns the ENaC function is inhibited and begins after the absorption of secretions of airways [52].

Potassium Ion Transport: In the respiratory epithelium, there are 30 types of potassium channels on both sides of the membrane [54-56]. These are divided into three main groups having six transmembrane domains (calcium dependent channels - KCa and voltage regulated - Kv), four transmembrane domains (two-pore channels - K2P) and two transmembrane domains (inwardlyrectifying channels - Kir) [32,54]. From the apical side there are only two-pore channels (K2P) [54]. In the respiratory epithelium there are also channels responsible for maintaining the potential of TREK-1 (TWIK-related $\mathrm{K}^{+}$channels), TWIK-1 and TWIK-2 (tandem P-domain weak inward rectifying $\mathrm{K}$ channel). TREK-1 is opened by stretching of the cell membrane and/or by cell swelling [56]. The conduction of the channel is reduced by an increase in the extracellular concentration of calcium and magnesium ions. The activity of TWIK-2 depends on the potential of the membrane and it is inhibited by acidification of the cytoplasm [57]. Secretion of potassium in the airways takes place through the $\mathrm{K}^{+}-\mathrm{H}^{+}$proton-pot exchanger, the sodium-potassium pump and sodium-potassium chloride cotransporter [44]. Movement of potassium cations through the cell membrane affects the absorption of sodium ions as well as the secretion of chloride and bicarbonate ions. The basolateral flow of potassium ions is also important for both the absorption and secretion processes of ions, water and proteins into the ASL fluid [56-58]. Potassium channels are involved in maintaining electrochemical strength through the transepithelial ion transport [32,54,56-58].

Chloride Ion Transport: The chloride channel CFTR (cystic fibrosis transmembrane conductance regulator), placed on the apical side of the non-ciliated epithelial cells, plays an important role in the transport of chloride ions $[5,10,12,18]$. In addition to ion transport, it is also responsible for regulating the expression and activity of other membrane transporters, including ENaC, affecting ATP transport and acting on mucus secretion [5,33,42,48,52]. CFTR protein processing defect is complicated and affects the activity of all cells in the respiratory tract $[4,10,13,28]$. CFTR plays a regulatory function in epithelium in the mechanism of nucleotide signaling, especially changes in siRNA quality and quantity [45]. CFTR is permeable to $\mathrm{Cl}$ - and $\mathrm{HCO}$ - ions, at a $4: 1$ ratio $[29,45]$. The CF (cystic fibrosis) gene is located on chromosome 7. The CFTR consists of two repeating motifs, each consisting of 6 transmembrane domains (TMD1, TMD2), two cytoplasmic nucleotide binding domains (NBD1, NBD2) and one regulatory domain (R). The activators of the CFTR channel include: ATP, forskolin, genistein, phloxin, apigenin, resolvin D while inhibitors are: glibenclamide, arachidonic acid and ibuprofen [45]. Changes in CFTR activity seem to be the main factor limiting chloride transport [5,9-10,24,48].

The secretion of chloride ions through cell membranes is associated with the secretion of water, which complements ASL
$[5,10,13]$. The loss of the CFTR function reduces the effective transport of $\mathrm{Cl}^{-}$and HCO3- $[13,24,48]$. CFTR inhibits the activity of $\mathrm{ENaC}$, thereby increasing permeability to sodium ions, which contributes to the hyperabsorption of $\mathrm{Na}+$ ions and the development of pulmonary diseases with consistent ASL retention $[10,48,52,57]$. Proper secretion of chloride ions requires the coparticipation of a sodium-potassium cotransporter and a sodiumpotassium pump [5,52]. The chloride ion from the submucosal space penetrates into the cell through the $\mathrm{Na}^{+} / \mathrm{K}^{+} / 2 \mathrm{Cl}^{-}$cotransporter $[2,45]$. The accompanying ions are then removed through the sodium-potassium pump located in the basal membrane, and the chloride ions are secreted into the airway lumen by CFTR and other chloride channels (e.g., ClC) $[24,41]$. The action of the sodiumpotassium pump located on the basolateral side of the cells involves transporting sodium to the outside of the cell, and potassium into the interior and maintains an electrochemical gradient that keeps the chloride ions inside the cell $[7,13,44]$.

Bicarbonates Ion Transport: In the airways, bicarbonate secretion plays a signficant role for gas exchange and $\mathrm{pH}$ changes in the ASL [37]. It also plays an important part in the endocytosis processes in mucosal cells. The secretion of these ions depends mainly on the concentration of cAMP and the transport of chloride ions [3]. A hydrogen proton and HCO3- anion are formed from carbon dioxide and water under the influence of carbonic anhydrase (EC 4.2.1.1) [13]. The protons are transported through the $\mathrm{Na}^{+} / \mathrm{H}^{+}$ exchanger in the basolateral membrane, while the anions mainly go through the CFTR in the apical membrane. $\mathrm{Na}^{+} / \mathrm{K}^{+}$ATPase action creates a chemical force for the exchanger [3]. However, the functioning of the basic potassium channels and the $\mathrm{Na}^{+} / \mathrm{K}^{+} / 2 \mathrm{Cl}^{-}$ cotransporter regulates the $\mathrm{HCO}_{3}^{-}$flow [5].

Absorption of $\mathrm{HCO}_{3}$ ions occurs among other means through the $\mathrm{K}+/ \mathrm{H}+$ exchanger and the $\mathrm{Cl}-/ \mathrm{HCO}_{3}$ - exchanger, independent of $\mathrm{Na}+$ in the base membrane [3,31]. However, in the apical membrane this transport is associated with the functioning of potassium channels [55]. Aldosterone, angiotensin, sodium transport and acidification influence the secretion of bicarbonates in the epithelium, however only acetylcholine in the respiratory epithelium has a significant stimulating effect on the excretion processes [22].

Calcium Ion Transport: The transport of calcium ions is essential for the functioning of the whole organism [30,33]. The calcium movement takes place by a paracellular route (an electrochemical gradient) or a transcellular route when calcium is absorbed or excreted on both sides of the membrane. In the airways, intracellular transport of $\mathrm{Ca}^{2+}$ ions is involved in the formation of ASL and the secretion of mucins and respiratory processes associated with muscle contraction and relaxation [30]. Additionally, in epithelial cells, changes in the concentration of calcium cations play a regulatory role for CFTR activity and regulatory factors [30].

Water Transport: Water transportin the respiratory epithelium is associated with the active transport of $\mathrm{Na}^{+}$ions and takes place from the apical to the basolateral $[4,18]$. Under the influence of $\mathrm{Cl}^{-}$secretion, water movement occurs from basal to apical [5]. The water transport in the airways enables air hydration, regulation of the height and density of the ASL, as well as the maintenance of an 
effective mechanism for cleaning the bronchial tree [8,27]. Water absorption makes it possible to maintain the proper viscosity of mucus on the surface of cells [27]. The transport of water is also carried out by means of a transcellular pathway [8]. Aquaporins are located in various parts of the airways [8,27]. Aquaporin 1 is located in the endothelium of the lung vessels and maintains the appropriate hydration status of the vesicles. Aquaporin 3 occurs in the airways and provides hydration of the air. Aquaporin 5 is present in submucosal gland cells and is involved in maintaining the common function of the airways [5,58]. Aquaporin 9 is present in the cells of the alveoli. In newborns, from the moment of the first breath, water transport through AQPs is necessary [53]. After this moment, the lungs begin to actively transport $\mathrm{Na}+$ ions [53], while water should be immediately removed from the alveoli and airways [3].

In adults, approximately $700 \mathrm{ml}$ of water is exhaled diurnally in the form of water vapor from the surface of the respiratory epithelium [25-26]. As a result, osmolality of ASL begins to exceed the osmolality of the interstitial space [53]. Sodium chloride is concentrated, which is the driving force behind the resulting osmotic gradient $[2,57]$. However, it should be noted that the continuity of the airway surface area is changing and is different [17]. The respiratory epithelium regulates the fluid lining of the airways [4$5,18,21,27]$. The epithelium can regulate the height and volume of the fluid without drastic changes in ion transport [2,8-9]. It is suggested that the upper layer of ASL contains high concentrations of ions above $100 \mathrm{mM}$, to ensure protection against colonization of bacteria and additionally to activate bactericidal agents, while the PCL layer contains $\mathrm{NaCl}$ in an amount below $50 \mathrm{mM}$, which ensures and maintains effective transepithelial transport of ions and water $[1,22-26,33,59]$. This hypothesis explains the possibility of adjusting the height and viscosity of the liquid lining in the entire respiratory tract $[9,46]$.

\section{Cough Reflex}

Coughing is an extremely important natural defense reaction. This is the rapid expulsion of air from the lungs combined with an accompanying noise. This reflex allows the removal of foreign bodies from the larynx, trachea and bronchi, preventing them from entering the respiratory system [60-61]. The resulting sudden air movement can reach a speed up to $6-22 \mathrm{~km} / \mathrm{h}$ and removes foreign particles from the respiratory tract that irritated the

\section{Summary}

Table 2: Drugs affecting ASL composition [12,20,42,49,63]. cough receptors nerve endings $[60,62]$. During the initiation of the cough reaction, rapidly-adaptive mechanoreceptors (RARs) and C fibers located in the larynx, trachea and bronchi participate, while the slowly-adaptive mechanoreceptors (SARs) are most likely responsible for the inhibition of this reflex $[55,60,62]$. The cough receptors are: transient receptor potential vanilloid 1 (TRPV1), transient receptor potential cation channel, Subfamily A, Member 1 (TRPA1) and acid sensing ion channel receptor 3 (ASIC3). All these receptors is sensitive to mechanical factors (in major airways) and chemical factors (in smaller ones) and are a source of nerve impulses [60-61]. Sensory signals are transmitted mainly by the afferent nerve fibers in the direction of the medulla where the cough center is stimulated $[55,60,62]$.

The main neurotransmitters secreted by stimulation of cough receptors are tachykinins: neurokinin A, substance $\mathrm{P}$ and calcitonin gene related peptide (CGRP) [34,55]. These substances act to increase blood flow, shrink vessels and muscles, eosinophil chemotaxis and release of inflammatory factors from immunocompetent cells $[34,39,60]$. It has been proven that during respiratory infections, mucus overproduction occurs and the mechanisms associated with mucociliary clearance are impaired $[18,23]$. Increased production of semi-liquid lining with a changed composition additionally irritates the cough receptors, increasing the frequency of the cough, consequently leading to over-reactivity $[25,59]$. A long-lasting cough affects changes in the composition of mucus and can even affect the reconstruction of the airways and alveoli as well as the expansion of the network of blood vessels and nerve fibers $[60,62]$. Mechanical cleansing of the airways is associated with effective mucociliary clearance and transport of ions and water [49-50]. Changes in transepithelial transport of ions, absorption of sodium ions and secretion of chloride ions (called the hypothesis of ionic support of cough), participate in the cough reflex in response to the retention of mucus in the bronchioles $[6,25,49,59]$. Secretion processes can be changed into absorption processes under the influence of physical and chemical stimuli [6$7,22,25,49-50]$. The combination of changes in ion transport, mucus secretion and regulation of its height, viscosity and volume, as well as changes in smooth muscle tone in the integrated physiological response, are elements dealt with by the nervous, endocrine and immune systems contained in the airway wall and are sometimes referred to as the local intra-community regulatory system $[7,12,17,22,25,46,48-49]$.

\begin{tabular}{|c|c|c|}
\hline Drug & Mechanism of Action & Administration \\
\hline Ambroxol/ & $\begin{array}{c}\downarrow \text { viscosity of mucus } \\
\uparrow \text { secretion of hydrated mucus } \\
\uparrow \text { production of surfactant } \\
\text { Bromhexin }\end{array}$ & p.o., aerosol beats of cilia \\
& alleviated by cough reflex & p.o., aerosol \\
\hline$N$-acetylcysteine & $\begin{array}{c}\downarrow \\
\end{array}$ & \\
\hline
\end{tabular}




\begin{tabular}{|c|c|c|}
\hline $\begin{array}{c}\text { Mesna } \\
\text { (2-mercaptoethanesulfonate) }\end{array}$ & $\begin{array}{c}\text { binds water molecules in the ASL } \\
\downarrow \begin{array}{c}\text { viscosity of mucus } \\
\uparrow \text { secretion of mucus }\end{array}\end{array}$ & aerosol \\
\hline Guaiacol, guaifenisine & $\begin{array}{c}\text { le } \downarrow \text { secretion of mucus } \\
\text { antiseptic properties } \\
\text { expectorant }\end{array}$ & p.o. \\
\hline Dorrnase alpha (EC 3.1.21.1) & $\begin{array}{c}\text { cuts extracellular DNA } \\
\downarrow \text { viscosity of inflammatory mucus }\end{array}$ & aerosol/nebulization \\
\hline Codeine & $\begin{array}{c}\uparrow \text { secretion of hydrated mucus } \\
\text { alleviates cough reflex }\end{array}$ & p.o. \\
\hline Glucocorticoids & $\begin{array}{c}\uparrow \text { production of mucins } \\
\uparrow \text { production of surfactant } \\
\uparrow \text { MCC }\end{array}$ & aerosol, p.o. \\
\hline
\end{tabular}

Dynamic changes in the composition and volume of ASL are a protective element for the airway epithelium [1-2,5,46]. Disruption of this process leads to changes in ASL, development of an inflammatory response and initiation of cough $[12,32,35,40]$. It is proven, that in neonates, the adsorption of sodium ions and water, as well as the secretion of chloride ions is necessary to take the first breath $[51,53]$. The proper operation of CFTR and ENaC channels on the surface of the airways is crucial to maintain patency as well as proper gas exchange $[4-5,10,33]$. Each disruption of transepithelial ion and water transport carries with it health consequences $[3,9,17]$. The administration of drugs to the bronchial tree mediates with the transport of ions and water (Table 2) [42,63]. Particularly noteworthy is the modern therapeutic approach, administered locally and with reduced drug dosages help guarantee effective action at the site of administration [36,60,47].

\section{References}

1. Balestrazzi A, Malandrini A, Martone G, Marigliani D, Caporossi T, et al. (2014) Capsule Contraction Syndrome with a Microincision Foldable Hydrophilic Acrylic Intraocular Lens: Two Case Reports and Review of the Literature. Case Rep Ophthalmol 5(3): 329-335.

2. Aose M, Matsushima H, Mukai K, Katsuki, Gotoh N, et al. (2014) Influence of intraocular lens implantation on anterior capsule contraction and posterior capsule opacification. Journal of Cataract \& Refractive Surgery 40(12): 2128-2133.

3. Altintas AG and Dal D (2010) Capsule contraction syndrome in Behcet's disease. Int J Ophthalmol 3(4): 358-360.

4. Zinkernagel M, Papazoglou A, Patel CK (2013) Bimanual anterior segment revision surgery for anterior capsule contraction syndrome associated with anterior flexion of intraocular lens haptics. Eye (Lond) 27(12): 1388-1390.

5. Tsinopoulos IT, Tsaousis KT, Kymionis GD, Symeonidis C, Grentzelos MA, et al. (2010) Comparison of anterior capsule contraction between hydrophobic and hydrophilic intraocular lens models. Graefes Arch Clin Exp Ophthalmol 248(8): 1155-1158.

6. Mönestam EI (2009) Incidence of dislocation of intraocular lenses and pseudophakodonesis 10 years after cataract surgery. Ophthalmology 116(12): 2315-2320.

7. Kumar A, Freeman M, Kumar V, Ramanathan US (2008) In the bag IOL dislocation following uncomplicated phacoemulsification. Cont Lens Anterior Eye 31(2): 103-106.

8. Cochener B, Jaccq PL, Colin J (1999) Capsule contraction after continuous curvilinear capsulorhexis: Poly (methyl methacrylate) versus silicone intraocular lenses. J Cataract Refract Surg 25 (10): 1362-1369.
9. Choi M, Lazo MZ, Kang M, Lee J, Joo CK (2018) Effect of number and position of intraocular lens haptics on anterior capsule contraction: A randomized, prospective trial. BMC Ophthalmol 18(1): 78.

10. Coelho RP, Zanatto MC, Paula JS, Romão E (2005) Spontaneous late inthe-bag intraocular lens dislocation after can-opener capsulotomy: case report. Arq Bras Oftalmol 68(6): 864-866.

11. Zhu XJ, Chen MJ, Zhang KK, Yang J, Lu Y (2016) Elevated TGF- $\beta 2$ level in aqueous humor of cataract patients with high myopia: Potential risk factor for capsule contraction syndrome. J Cataract Refract Surg 42(2): 232-238.

12. Zhang K, Zhu X, Chen M, Sun X, Yang J, et al. (2016) Elevated Transforming Growth Factor- $\beta 2$ in the Aqueous Humor: A Possible Explanation for High Rate of Capsular Contraction Syndrome in High Myopia. J Ophthalmol 2016: 5438676.

13. Banh A, Deschamps PA, Gauldie J, Overbeek PA, Sivak JG, et al. (2006) Lens-specific expression of TGF-beta induces anterior subcapsular cataract formation in the absence of Smad3. Investigative Ophthalmology and Visual Science 47(8): 3450-3460.

14. Hayashi Y, Kato S, Maeda T, Kaiya T, Kitano S (2005) Immunohistologic study of interleukin- 1 , transforming growth factor- $\beta$, and $\alpha$-smooth muscle actin in lens epithelial cells in diabetic eyes. Journal of Cataract and Refractive Surgery 31(11): 2187-2192.

15. Werner L, Pandey SK, Escobar-Gomez M, Visessook N, Peng Q et al. (2000) Anterior capsule opacification: A histopathological study comparing different IOL styles. Ophthalmology 107(3): 463-471.

16. Gao Y, Dang GF, Wang X, Duan L, Wu XY (2015) Influences of anterior capsule polishing on effective lens position after cataract surgery: A randomized controlled trial. Int J Clin Exp Med 8(8): 13769-13775.

17. Kim SY, Yang JW, Lee YC, Kim SY (2013) Effect of haptic material and number of intraocular lens on anterior capsule contraction after cataract surgery. Korean J Ophthalmol 27(1): 7-11.

18. Hayashi K, Hayashi H (2005) Comparison of the stability of 1-piece and 3-piece acrylic intraocular lenses in the lens capsule. J Cataract Refract Surg 31(2): 337-342.

19. Tsinopoulos IT, Tsaousis KT, Kymionis GD, Symeonidis C, Grentzelos MA, et al. (2010) Comparison of anterior capsule contraction between hydrophobic and hydrophilic intraocular lens models. Graefes Arch Clin Exp Ophthalmol 248(8):1155-1158.

20. Tsinopoulos I, Symeonidis C, Frangou E, Dimitrakos SA (2008) Capsule contraction syndrome in eight cases of hydrophobic one-piece intraocular lens implantation. Clin Exp Optom 91(5): 469-472.

21. Sacu S, Menapace R, Findl O (2006) Effect of optic material and haptic design on anterior capsule opacification and capsulorrhexis contraction. Am J ophthalmol 141(3): 488-493.

22.Zéboulon P, Gatinel D (2018) Unusual Internal Astigmatism Due to Severe Capsule Contraction Syndrome. J Refract Surg 34(1): 65-67. 
23. Page TP, Whitman J (2016) A stepwise approach for the management of capsular contraction syndrome in hinge-based accommodative intraocular lenses. Clin Ophthalmol 10: 1039-1046.

24. Altintas AGK, Ilhan C (2018) Haptic Reposition with Laserposterior Capsulotomy in Eyes with Capsular Contraction without Anterior Capsular Phimosis. Madridge J Ophthalmol 3(1): 39-41.

25. Deokule SP, Mukherjee SS, Chew CK (2006) Neodymium: YAG laser anterior capsulotomy for capsular contraction syndrome. Ophthalmic Surg Lasers Imaging 37(2): 99-105.

26. Kim HD, Kim JM, Jung JJ (2017) Complete occlusion of anterior capsulorhexis after uneventful cataract surgery, treated with YAG laser capsulotomy. BMC Ophthalmol 17(1): 233.

27. Altintas AGK, Dal D, Simsek S (2008) Significant intraocular lens folding due to severe capsular contraction. Jpn J Ophthalmol 52(2): 134-136.

28. Wang W, Chen M, Wang Y, Yao K (2015) Bilateral capsule contraction syndrome-induced ciliary body detachment. Cataract Refract Surg 41(2): 468-470.

29. Wesolosky JD, Tennant M, Rudnisky CJ (2017) Rate of retinal tear and detachment after neodymium: YAG capsulotomy. J Cataract Refract Surg 43(7): 923-928

\section{ISSN: 2574-1241}

DOI: 10.26717.BJSTR.2019.14.002543

Iga Hołyńska Iwan. Biomed J Sci \& Tech Res

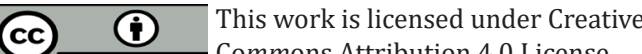
Commons Attribution 4.0 License

Submission Link: https://biomedres.us/submit-manuscript.php
30. Gerten G, Schultz M, Oberheide U (2016) Treating capsule contraction syndrome with a femtosecond laser. J Cataract Refract Surg 42(9): 12551261

31. Schweitzer C, Tellouck L, Gaboriau T, Leger F (2015) Anterior capsule contraction treated by femtosecond laser capsulotomy. J Refract Surg 31(3): 202-204.

32. Page TP, Whitman J A (2016) Stepwise approach for the management of capsular contraction syndrome in hinge-based accommodative intraocular lenses. Clin Ophthalmol 10: 1039-1046.

33. Altintas AGK, Ozcan PY, Koklu G (2014) Unusual features of developed capsule contraction syndrome in long term follw up period. Journal of Glaucoma-Cataract 9(3): 210-214.

34. Sudhir RR and Rao SK (2001) Capsulorhexis phimosis in retinitis pigmentosa despite capsular tension ring implantation. J Cataract Refract Surg 27(10): 1691-1694.

35. Moreno-Montañés J, Sánchez-Tocino H, Rodriguez-Conde R (2002) Complete anterior capsule contraction after phacoemulsification with acrylic intraocular lens and endocapsular ring implantation. J Cataract Refract Surg 28(4): 717-719.

36. Altintas AGK, Omay AE,Celik S (2017) Spontaneous Late Intraocular lens and capsule tension ring dislocation. Turk J Ophthalmol 47(2): 106-109.

$\begin{array}{ll}\text { BIOMEDICAL } & \text { Assets of Publishing with us } \\ \text { RESEARCHES } & \text { - Global archiving of articles } \\ & \text { - Immediate, unrestricted online access } \\ & \text { - Rigorous Peer Review Process } \\ & \text { - Authors Retain Copyrights }\end{array}$

